\title{
A PERCEPÇÃO DE GESTÃo DE NEGÓCIOS EM UM GRUPO DE PEQUENOS CAFEICUTORES FAMILIARES
}

\author{
The Perception of Business Management at Group of a Small Family Farmers Coffee
}

\begin{abstract}
RESUMO
O objetivo deste artigo é identificar a maturidade da gestão de pequenas unidades agricultoras cafeeiras do leste de Minas Gerais. Foi uma pesquisa quantitativa, descritiva, com corte transversal. Os dados primários foram obtidos através da aplicação de questionário composto de perguntas baseadas nas quatro perspectivas do modelo Balanced Scorecard (BSC). O questionário foi respondido por 58 agricultores. Para confirmar a presença de maturidade da gestão (Aprendizado e Crescimento, Clientes, Interna e Financeira) foi feito teste de correlação de Spearman e regressão ordinal para cada variável explicativa. Os resultados apontaram que, nesse grupo amostral, não há maturidade da gestão empresarial, segundo as quatro perspectivas do BSC. Assim sendo, é possível admitir que, essa amostra de agricultores não utiliza os parâmetros do BSC como critério para decidir os rumos de seu negócio.-
\end{abstract}

Isabelle Werner de Lemos

Fucape Business School

isabellewl@hotmail.com

Arilda Teixeira

Fucape Business School

arilda@fucape.br

Recebido em: 20/11/2019. Aprovado em: 06/07/2020.

Avaliado pelo sistema double blind review

Avaliador científico: Paulo Henrique Montagnana Vicente Leme

DOI: 10.48142/2238-68902019v21n1-3p173185

\begin{abstract}
This paper aims to identify the management maturity of the small coffee farming units in eastern Minas Gerais state. It was a quantitative, descriptive, cross sectional survey. The primary data were obtained through the application of a questionaire composed of questions based on the four perspectives of the Balanced Scorecard (BSC) model. The questionnaire was answered by 58 farmers. To confirm the presence of management maturity (Learning and Growth, Clients, Internal, and Financial) Spearman's correlation test and ordinal regressions were performed for each explanatory variable. The results showed that, in the sample group, there is no maturity in business management, according to the four perspective of the BSC. Thefore, it is possible to admit that this sample of farmers does not use the BSC parameters as criterion to decide the direction of their business.
\end{abstract}

Palavras-Chave: Modelo de Gestão. Produtor Familiar Cafeeiro. Balanced Scorecard.

Keywords: Management Model. Small Coffee Farmers. Balanced Scorecard.

\section{INTRODUÇÃO}

Ainda é traço característico da pequena agricultura familiar no Brasil a baixa escolaridade do agricultor e tratamento indistinto para o orçamento da atividade produtiva e o orçamento familiar. Essas características dificultam o planejamento estratégico necessário para acompanhar as tendências do mercado com sustentabilidade do negócio. A despeito de que nesse segmento de agricultura seja intrínseco uma estreita relação entre os objetivos da família e os da empresa, os agricultores precisam entender e separar as necessidades individuais das empresariais (RODER; SILVA, 2013; LOURENZANI, 2005; LOURENZANI; QUEIROZ; SOUZA FILHO, 2005).
Mas a literatura já apresenta indicações de que o grau de instrução do agricultor pode contribuir para a eficiência do seu negócio. Linh (2012) analisou a eficiência técnica de agricultores familiares de arroz no Vietnam, usando o modelo DEA e o método bootsrap. Encontrou que a eficiência daquele grupo de agricultores era determinada pela escolaridade do agricultor e pelos aspectos regionais favoráveis (clima, relevo, e/ou estação do ano).

Gaitán-Cremaschi et al., (2018) estudaram a sustentabilidade da agricultura familiar cafeeira do Vietnam. Identificaram que a sustentabilidade dessa agricultura depende do porte das fazendas e das condições que agricultor dispõe para mantê-las eficientes - as características socioeconômicas e habilidades gerenciais dos agricultores. 
Ho, Hoang, Wilson e Nguyen (2017) compararam a eficiência produtiva de três sistemas de produção de café vietnamita - a monocultura, a sincronização e a segregação. Identificaram que a insegurança alimentar induz os cafeicultores a diversificarem suas lavouras. E, também, que apesar de a ineficiência dos três ser de $18 \%$, há uma variância significativa entre eles. O sistema sincronizado é o mais eficiente. A monocultura é menos eficiente que o sistema sincronizado porque nele há economia de escopo entre a lavoura de café familiar e a lavoura industrial. O sistema menos eficiente é o cultivo segregado de café e arroz.

Rosa et al., (2017) analisaram a adoção de boas práticas do produtor agrícola familiar cafeeiro da Associação de Agricultores de Santo Antônio do Amparo (AFASA), em Minas Gerais. Seguindo as boas práticas, esses produtores atingiram qualidade para entrar em mercados de maior valor agregado, e na sequência, a certificação de produtores com boas práticas agrícolas.

Para Frezatti et al., (2014) os parâmetros de desempenho empresarial do Balanced Scorecard (BSC) proporcionam ao proprietário amparo para elaborar estratégia para administrar, planejar e controlar suas atividades cotidianas - percepção estratégica do seu negócio.

Entende-se que a maturidade de uma gestão é reflexo de um amplo conhecimento sobre o negócio que ela conduz. Nesse contexto, o BSC é um modelo gerencial sistêmico que interpõe a visão estratégica à operacional de um negócio (COE; LETZA, 2014; KAPLAN; NORTON, 2006; LOURENZANI; PINTO, 2006). Lourenzani (2005) e Queiroz (2004) aplicaram os parâmetros do BSC para identificar o desempenho da agricultura familiar.

A Empresa de Assistência Técnica e Extensão Rural do Estado de Minas Gerais - EMATER-MG (2016) considera que os dificultadores para os agricultores familiares desenvolverem-se economicamente são o gerenciamento, a organização, a estruturação legal, as práticas de produção, a redução de custos, e otimização da utilização de recursos. Sendo assim, as chances de sucesso desse segmento dependem de sua capacidade de gerenciar tecnicamente seus negócios. A EMATER-MG (2016) enfatiza a importância de se profissionalizar o agricultor familiar como meio para impulsionar o desenvolvimento agrícola, e ampliar e as cadeias produtivas.

Roder e Silva (2013), Lourenzani (2005), Lourenzani, Queiroz e Souza Filho (2005), e Queiroz (2004), apontaram a baixa frequência de utilização das medidas de desempenho do BSC na gestão de agricultura familiar.

Lourenzani (2005), Lourenzani, Queiroz e Souza Filho (2005) e Queiroz (2004) aplicaram a metodologia do BSC em agriculturas familiares, da estratégia à ação. Entretanto, não confirmaram que esses agricultores têm conhecimento adequado para a implantação e/ou sustentação desse modelo de gestão para esse segmento da economia.

A agricultura familiar é muito diversa. Com isso, consegue participar de vários polos de atividade econômica. Se aprimorar suas técnicas de gestão tem fôlego para aproveitar as oportunidades de negócios, e contribuir para o crescimento econômico (LOURENZANI, 2005; LOURENZANI; QUEIROZ; SOUZA FILHO, 2005). Contudo, o insuficiente conhecimento gerencial da agricultura familiar, a impede de adotar um gerenciamento de sucesso capaz de aproveitar os benefícios oferecidos pelo mercado.

$\mathrm{O}$ contexto descrito pela literatura apresentada sugere que a pequena agricultura familiar - inclusive a cafeeira, objeto de estudo deste artigo - tem dificultadores e potencialidades. O tratamento adequado - técnicas de gestão e capacidade cognitiva - são os caminhos para que se torne uma atividade econômica viável e rentável para seus executores.

Contudo, para o grupo de 58 pequenos cafeicultores familiares do leste de Minas Gerais, ainda não há estudos sobre seu modelo de negócio. Nesse grupo todos os cafeicultores têm baixa escolaridade, desconhecem técnicas de gestão, e praticam a agricultura de forma intuitiva. Sendo assim, e por ser a lavoura de café uma das atividades econômicas mais tradicionais na economia brasileira, cabe uma análise sobre ele, inclusive para ajudá-lo a identificar as possibilidades que sua atividade econômica oferece.

Esse contexto suscitou o seguinte questionamento: Os agricultores cafeeiros familiares da amostra deste estudo utilizam os parâmetros do BSC para conduzir seus negócios? Para responder esta pergunta, este artigo tem como objetivo identificar a maturidade da gestão desses 58 agricultores.

\section{REFERENCIAL TEÓRICO}

\subsection{Aspectos da Gestão da Pequena Agricultura Familiar Brasileira}

Em meados do século XIX, a produção de café no Brasil ganhou força com a tecnologia de produção trazida pelos imigrantes japoneses e europeus entre 1889 e 1930. A cafeicultura passou a ser o carro chefe da economia nacional (SPROESSER et al., 2004).

$\mathrm{Na}$ esteira desse processo vieram as oportunidades para a agricultura familiar sair do estágio de campesinato e passar para a de atividade econômica com fins lucrativos

Organizações Rurais \& Agroindustriais, Lavras, v. 21, n.1-3, p. 173-185, 2019 
(TOMEI; LIMA, 2014; WANDERLEY, 2009; FAUTH, 2008; FINATTO; SALAMONI, 2008; SANTOS; SILVEIRA, 2008; KAGEYAMA, 2008; ABRAMOVAY; VEIGA, 1999; KULAWCZUK, 1998; PETRIN; GANNON, 1997).

Sothe, Dresel e Dill (2014) definem a agricultura familiar como um grupo composto somente por familiares, que executam atividade agrária para obter recursos financeiros para sobreviverem.

Queiroz (2011) enfatiza que na história da agricultura familiar brasileira atravessam as escolhas governamentais erradas, a falta de informação, e de investimento na educação rural.-Essa sucessão de equívocos, além de fomentar a desigualdade social, cerceou as oportunidades para expansão e sustentabilidade dos negócios familiares agrícolas.

Diante do descrito é possível compreender a importância de o agricultor familiar conhecer e aplicar técnicas de gestão de negócios para alcançar a maturidade gerencial necessária à sustentabilidade do seu negócio. Dentre elas, estão as 4 perspectivas do BSC.

Esse histórico da cultura agrícola familiar expõe um grave obstáculo para a uma bem-sucedida administração das atividades econômicas da produção rural, (TEIXEIRA; PEREIRA, 2014; SOTHE; DRESEL; DILL, 2014; EYERKAUFER; OLINQUEVITCH, 2007; GUILHOTO, 2007; LOURENZANI, 2006; WANDERLEY, 2006; QUEIROZ, 2004).

Transportando o contexto de gestão organizacional para os 58 agricultores familiares cafeeiros da região leste de Minas Gerais, identifica-se que a falta de preparo desse grupo para adotar técnicas empresariais é um obstáculo para que adquiram/desenvolvam a competitividade para enfrentarem o mercado. Parte dessa dificuldade explicase pelo hábito de trabalharem como os pais trabalhavam. Assim, vêm ratificando culturas passadas e ultrapassadas que obstaculizam o avanço da sua atividade produtiva (SOTHE; DRESEL; DILL, 2014; TEIXEIRA; PEREIRA, 2014; EYERKAUFER; OLINQUEVITCH, 2007; LOURENZANI, 2006; QUEIROZ, 2004; WANDERLEY, 2006).

O proprietário rural necessita profissionalizar suas rotinas administrativas, procurando modelos de gerenciamento financeiros, identificando a missão, visão, e valor da propriedade,-para que possa operacionalizar lucrativamente as atividades da propriedade. Se as ações cotidianas não se ajustam às tendências do mercado, o sucesso da gestão fica comprometido (LOURENZANI, 2005).

$\mathrm{O}$ agricultor precisa ver a propriedade como um negócio. Ou seja, deve manter a inter-relação entre insumo, produção, transformação (agroindústria), e distribuição; executando as atividades produtivas com técnicas de gestão que garantam o sucesso de suas decisões gerenciais (ROMEIRO, 2002).

Petry e Nascimento (2009) afirmam que é grande a probabilidade de implantação e não continuação do modelo de gestão entre pequenos produtores rurais. Todavia, existem proprietários que implementam e valorizam seus modelos de gestão, mesmo quando existe a sucessão. Para que a implantação de um modelo de gestão seja bemsucedido é necessário que haja iniciativa do proprietário, para alocar, de forma eficiente, os recursos limitados; e adequar o ambiente da propriedade para dar continuidade ao processo de implantação. (ACS; KALLAS, 2007; LOURENZANI, 2005; CROZATTI, 1998;).

Um adequado modelo de gestão é aquele que deriva da cultura organizacional e que possua flexibilidade para mudanças. Para Lourenzani (2005), o sistema de processamento de mudanças define a estrutura sistêmica do empreendimento rural, e permite identificar os elementos internos que estimulam o negócio; além de apontar a responsabilidade do administrador, para decidir qual alocação de recursos potencializa o produto final (LOURENZANI, 2005; ROMEIRO, 2002; MURDOCH, 2000).

\subsection{Balanced Scorecard (BSC)}

Segundo Coe e Letza (2014), a maturidade gerencial de um negócio, vai além da compreensão dos dados fornecidos por medidas de desempenho. Ela aponta as melhores opções para o gestor escolher e/ou implantar estratégicas adequadas para o sucesso do negócio. Amplia-se a capacidade de sucesso de um negócio quando há informações suficientes para tomada de decisão. No âmbito da gestão da pequena agricultura familiar, segundo Lourenzani (2005), o conceito de gestão estratégica não é amplamente utilizado - inclusive o modelo de negócios do BSC. Não se segue parâmetros de desempenho para avaliar a maturidade de gestão de maneira que o produtor rural entenda a sua propriedade como uma unidade produtiva que visa o lucro (ACS; KALLAS, 2007; OZGEN; MISKY, 2007).

Ainteração da visão estratégica coma operacionalização otimizadora proposta pelo BSC, pode ser implantada em qualquer organização, independentemente de sua estrutura ou tamanho é muito adequada para a agricultura familiar brasileira. Inclusive a cafeicultora (ZHANG; CHEN, 2016; COE; LETZA, 2014; NIVEN, 2011; ROHM; HALBACH, 2005; KAPLAN; NORTON, 2006; LOURENZANI, 2005).

O BSC aponta quatro medidas/perspectivas de desempenho. No âmbito da pequena agricultura familiar a relação família-negócio, em vários momentos, é conflitante, 
cabendo ao líder encontrar meios que acomodem as divergências para que os objetivos do negócio sejam alcançados. Esse confronto pode ser entendido como um dilema dos envolvidos com a administração rural devido à falta de percepção de negócios que esses agricultores têm (LOURENZANI, 2005).

Segundo Shadbolt e Rawlings (2000), usualmente, a agricultura familiar tem como objetivo primordial ser um negócio sustentável que atenda as aspirações familiares do presente, e das próximas gerações. Ou seja, deve ser sustentável no curto prazo para gerar riquezas para o longo prazo.

Neste artigo, optou-se em utilizar o conceito de sustentabilidade da gestão de dois dos principais autores da literatura sobre agricultura familiar, Lourenzani (2005) e Queiroz (2004), que mostram como as perspectivas do BSC são adequadas para interpretar a maturidade da gestão do modelo de negócios da amostra de agricultores da agricultura familiar cafeeira deste artigo. Ao explicar as 4 perspectivas do BSC, adota uma abordagem holística da agricultura familiar do setor cafeeiro, objeto de pesquisa deste estudo.

\subsubsection{Perspectiva Financeira}

Trata da finalidade estratégica de um empreendimento, buscando melhor resultados para os stakeholders através da redução das despesas e/ou aumento das receitas. Realidade que também se aplica aos administradores rurais, uma vez que também objetivam mais resultados financeiros; apesar de não empregarem técnicas de gestão para garanti-los (KAPLAN; NORTON, 2006; QUEIROZ, 2004). Para que a saúde financeira do empreendimento rural seja alcançada é preciso controlar a evolução dos custos (fixos e variáveis) conforme o comportamento das receitas. Portanto, os objetivos da perspectiva financeira são a lucratividade e a margem de contribuição da produção (LOURENZANI, 2005; QUEIROZ, 2004).

\subsubsection{Perspectiva Interna}

Identificar e acompanhar todos os processos internos da organização é fundamental para seu sucesso porque este conhecimento lhe permite acompanhar os que foram implementados e identificar os que precisam ser implantados. É o caminho para aumentar a produtividade do processo produtivo rural, e melhorar a qualidade dos produtos (QUEIROZ, 2004). Segundo Lourenzani (2005), essa perspectiva aponta a relação entre as estratégias escolhidas internamente e o mercado podendo entrar em harmonia com a perspectiva do cliente. As práticas de produção dos produtores rurais são os processos mais fáceis de compreender por eles, visto que convivem com as tarefas e mecanismos desde que pequenos.

\subsubsection{Perspectiva Cliente}

Evidenciar, em um contexto de pequena agricultura familiar, que os agentes do canal de distribuição devem ser considerados como clientes não é tarefa simples de se praticar. Assim, a tarefa de classificar a qualidade do café - Classificação Oficial Brasileira (COB) - é uma prática da perspectiva do cliente, do processo de gestão, que contribui para competitividade do negócio (SENAR, 2015; KAPLAN; NORTON, 2006; LOURENZANI, 2005; QUEIROZ, 2004).

A escolha do tipo de produção, manejo e até a forma de comercialização do grão afetam na qualidade do produto. Portanto, a atenção para a preferência do cliente é fundamental para que se alcance um valor de venda maior $o$ que, por sua vez, afeta diretamente a perspectiva financeira.

É essencial que essa perspectiva esteja alinhada às informações internas e externas do empreendimento rural, tais como: mercadológicas, governamentais e políticas. Ainteração dessas informações direcionará a estratégia do produtor (LOURENZANI, 2005). O objetivo da perspectiva cliente é fomentar a satisfação do cliente para sustentar a demanda do negócio e garantir preços competitivos (QUEIROZ, 2004).

\subsubsection{Perspectiva Aprendizado e Crescimento}

Essa perspectiva viabiliza as demais. Objetiva a inter-relação entre os ambientes, interno e externo. Uma vez identificadas as necessidades dos clientes e do ambiente interno da organização, pode-se identificar onde estão as falhas na infraestrutura, na habilidade dos colaboradores, no sistema informacional, e na cultura interna (KAPLAN; NORTON, 2006).

Nessa perspectiva, os produtores rurais não agregam tanto valor, não existe a cultura de crescimento pessoal e profissional, o que prejudica muito a compreensão de que conhecimentos gerenciais fazem parte da alavancagem de um negócio. Mas não deixa de ser essencial para abarcar as outras três perspectivas, pois o conhecimento e a aprendizagem são essenciais para acompanhar a evolução dos ambientes interno e financeiro (LOURENZANI, 2005; QUEIROZ, 2004).

É importante enfatizar que quanto maior a capacidade intelectual do proprietário rural, melhor sua adaptabilidade à utilização de técnicas de gestão. Quanto maior a escolaridade maior a capacidade de inovação e desenvolvimento de produção operacional e gerencial do empreendimento rural. Contudo, essa característica não elimina o conflito entre a busca da satisfação dos

Organizações Rurais \& Agroindustriais, Lavras, v. 21, n.1-3, p. 173-185, 2019 
membros da família, preservando a motivação no ambiente de trabalho, e a produtividade do processo produtivo (LOURENZANI, 2005; QUEIROZ, 2004).

A perspectiva de aprendizado e crescimento permeia a responsabilidade de desenvolver as outras perspectivas do BSC, o que segundo Queiroz (2004) e Lourenzani (2005) devem ser analisadas com muita cautela e desenvolvidas continuamente para que toda a metodologia obtenha sucesso.

\section{METODOLOGIA DA PESQUISA}

A região de Caparaó possui, aproximadamente, 36 mil pequenos cafeicultores, distribuídos em 63 municípios, numa área de 275 mil hectares. $80 \%$ deles possuem área de produção com menos de 20 hectares plantados. Os empregos gerados por essa atividade - 75 mil diretos e 156 mil indiretos - são importantes propulsores da economia local (INCAPER, 2017; MATA DE MINAS, 2017).

Para cumprir o objetivo deste artigo - identificar a maturidade da gestão de pequenas unidades agricultoras cafeeiras do leste de Minas Gerais - desenvolveu-se uma pesquisa quantitativa, descritiva, com corte transversal. O universo da pesquisa foram os agricultores de propriedades rurais com área igual ou menor que 4 módulos fiscais. A amostra foi composta por 58 pequenos proprietários agricultores cafeeiros rurais, que residem na região do CaparaóMG, e que se dispuseram a respondê-lo.

O perfil da amostra indica que a escolaridade predominante dos agricultores é ensino fundamental (48\%); $36 \%$, tem ensino médio; e $12 \%$ ensino superior. A faixa etária predominante é de 41 a 60 anos; e o tempo médio de trabalho na agricultura é de até 15 anos, $45 \%$ da amostra; e entre 16 e 30 anos, $35 \%$ - Tabela 1.

Os agricultores foram selecionados por conveniência, para responderem um questionário semiestruturado, com opções de resposta em escala Likert de 1 a 5 . Sendo 1, discordo totalmente, e 5 concordo totalmente. O conteúdo das questões foram as dimensões das quatro perspectivas do BSC (construtos) - aprendizado e crescimento, clientes, interna e, financeira - Quadro 1. Seguindo indicações de Lourenzani (2005) e Queiroz (2004), essas dimensões foram as 22 variáveis explicativas do modelo estimado.

As respostas das afirmativas do Quadro 1 são do tipo ordinal - medidas discretas (qualitativas) - com as quais é possível estabelecer uma relação de ordem não quantificável, sobre a percepção de negócios dos cafeicultores desta amostra. Para análise das dimensões do BSC, foram utilizadas a mediana e a moda estatística. Para verificar se há relação entre a percepção de negócio e os construtos (quatro perspectivas do BSC) foram utilizadas a correlação de Spearman e regressão ordinal.

TABELA 1 - Perfil da amostra

\begin{tabular}{|c|c|c|}
\hline Variável & Frequência & $\%$ \\
\hline \multicolumn{3}{|l|}{ ESCOLARIDADE } \\
\hline Ensino Fundamental - Até a $4^{\mathrm{a}}$ série & 16 & 27,6 \\
\hline Ensino Fundamental - Da $5^{\circ}$ a $8^{\mathrm{a}}$ série & 12 & 20,7 \\
\hline Ensino Médio & 21 & 36,2 \\
\hline Graduação em andamento & 2 & 3,4 \\
\hline Graduação concluída & 7 & 12,1 \\
\hline Total & 58 & \\
\hline \multicolumn{3}{|l|}{ IDADE } \\
\hline De 0 a 20 anos & 1 & 1,7 \\
\hline De 21 a 40 anos & 20 & 34,5 \\
\hline De 41 a 60 anos & 31 & 53,4 \\
\hline De 61 a 80 anos & 6 & 10,3 \\
\hline \multicolumn{3}{|l|}{ TEMPO DE NEGÓCIO } \\
\hline De 0 a 15 anos & 26 & 44,8 \\
\hline De 16 a 30 anos & 20 & 34,5 \\
\hline De 31 a 45 anos & 8 & 13,8 \\
\hline De 46 a 60 anos & 3 & 5,2 \\
\hline Acima de 60 anos & 1 & 1,7 \\
\hline
\end{tabular}

Fonte: Dados da pesquisa. Elaborado pelos autores

Cabe destacar que, a despeito de a região cafeicultora ser extensa e com 36 mil pequenos cafeicultores, a maioria absoluta não foi receptiva para responder o questionário aplicado fisicamente, in loco. Foram tentados contatos com os cafeicultores várias vezes, durante 4 meses, inclusive nas associações de classe, mas somente 58 se dispuseram a responder o questionário. E todos demonstraram dificuldade para entender o que as perguntas pediam.

Decidiu-se estimar os resultados mesmo com a amostra pequena, porque os testes estatísticos sinalizaram o que a literatura sobre pequena agricultura familiar aponta.

Foram feitas análises estatísticas até aprimorar os dados e torná-los adequados para diagnóstico. Primeiramente, identificou-se a frequência de respostas obtidas para variável dependente (Percepção de Negócio), para escolha da melhor função link. Como não se obteve resultados de acordo com as indicações de Marôco (2014), para que a análise não se tornasse enviesada, foi feito, para cada avaliação estatística, um teste com as 5 funções link. 
Iniciou-se a regressão ordinal com todas as variáveis (dimensões) em relação a Y1(Percepção de Negócio), e testou-se para cada função link. Mas os resultados não foram estatisticamente significantes. Para aprimorá-los, utilizou-se o teste de Sperman, conforme orienta Marôco (2014). Nesse teste houve variáveis estatisticamente significantes para explicar Y1. Paralelamente, realizou-se a regressão ordinal individualmente para cada variável independente, sempre identificando qual a melhor função link a ser aplicada. Com a regressão foram identificadas as variáveis significativas para explicar Y1. Em seguida, foram rodadas duas regressões: "Regressão Comum" e "Regressão Final".

\section{DADOS E DISCUSSÃO DOS RESULTADOS}

\subsection{Teste de Correlação}

Marôco (2014, p.25) cita que o teste de correlação de Spearman é adequado para estabelecer associação entre duas varáveis que sejam, no mínimo, ordinais, sem supor suas distribuições da frequência. Considera que para realizar uma regressão ordinal, deve-se usar como parâmetro de medida de associação o teste de Spearman, desconsiderando assim o resultado proporcionado pelo sistema SPSS Statistic no teste de Pearson - Tabela 2.

QUADRO 1 - Grau de concordância sobre as perspectivas de negócio do BSC

\begin{tabular}{|c|c|c|}
\hline CONSTRUTOS & VARIÁVEL & ITEM \\
\hline $\begin{array}{l}\text { VARIÁVEL } \\
\text { DEPENDENTE }\end{array}$ & Minha propriedade está preparada para enfrentar as mudanças do mercado (Percepção de negócio). & Y1 \\
\hline \multirow{4}{*}{$\begin{array}{l}\text { Perspectiva } \\
\text { Aprendizado e } \\
\text { Crescimento }\end{array}$} & Eu faço planejamentos técnicos para as safras para que a produção da lavoura melhore. & $\mathrm{AC} 1$ \\
\hline & Conheço as técnicas para melhorar os resultados da produção da minha lavoura. & $\mathrm{AC} 2$ \\
\hline & Pago cursos de aperfeiçoamentos para meus funcionários. & $\mathrm{AC} 3$ \\
\hline & Procuro orientação técnica dos órgãos que apoiam os produtores rurais. & $\mathrm{AC} 4$ \\
\hline \multirow{5}{*}{$\begin{array}{l}\text { Perspectiva } \\
\text { Clientes }\end{array}$} & Coloco em prática as mudanças técnicas que conheci através dos órgãos de apoio ao agricultor. & AC5 \\
\hline & Conheço as preferências e gostos de meus clientes. & Clientes 1 \\
\hline & $\begin{array}{l}\text { Modifico minha forma de conduzir o meu negócio como agricultor para atender às solicitações } \\
\text { dos meus clientes (corretor, cliente final, supermercados, cafeteiras, distribuidores, exportação). }\end{array}$ & Clientes2 \\
\hline & Tenho plano definido para enfrentar meus concorrentes. & Clientes 3 \\
\hline & Considero que meu produto é diferenciado (melhor) que o de seu concorrente. & Clientes 4 \\
\hline \multirow{6}{*}{ Perspectiva Interna } & Faço planejamento interno para me preparar para as mudanças no mercado. & Interna1 \\
\hline & Meu negócio tem Missão e objetivos definidos & Interna2 \\
\hline & Os processos de produção da minha propriedade estão totalmente definidos. & Interna3 \\
\hline & $\begin{array}{l}\text { Separo as atividades da produção agrícola da minha propriedade das atividades do dia-a-dia da } \\
\text { minha família. }\end{array}$ & Interna4 \\
\hline & Minha propriedade tem divisões de tarefas definidas (por talhão, forma de produção). & Interna5 \\
\hline & Minha propriedade cumpre as divisões de tarefas estabelecidas. & Interna6 \\
\hline \multirow{7}{*}{$\begin{array}{l}\text { Perspectiva } \\
\text { Financeira }\end{array}$} & Conheço os custos fixos da minha propriedade agrícola. & FIN1 \\
\hline & Conheço os custos variáveis da minha propriedade agrícola. & FIN2 \\
\hline & Conheço a receita que cada talhão dá. & FIN3 \\
\hline & $\begin{array}{l}\text { Planejo o atendimento das necessidades da minha propriedade conforme os resultados } \\
\text { financeiros da atividade agrícola da propriedade. }\end{array}$ & FIN4 \\
\hline & $\begin{array}{l}\text { Trato as necessidades financeiras da minha família separadamente das necessidades financeiras } \\
\qquad \text { da atividade agrícola da propriedade }\end{array}$ & FIN5 \\
\hline & $\begin{array}{l}\text { Tenho definido a forma para calcular o salário de cada membro da propriedade, inclusive o } \\
\text { meu, conforme a tarefa que desempenha na atividade agrícola da propriedade. }\end{array}$ & FIN6 \\
\hline & Planejo mudanças nos processos de produção para que a minha produção tenha menores custos & FIN7 \\
\hline
\end{tabular}

Fonte: Baseado em Queiroz (2004) e Lourenzani (2005), adaptado pela autora

Organizações Rurais \& Agroindustriais, Lavras, v. 21, n.1-3, p. 173-185, 2019 
TABELA 2 - Teste de spearman

\begin{tabular}{|c|c|c|}
\hline \multicolumn{3}{|l|}{ Rô de Spearman } \\
\hline \multirow[b]{2}{*}{ Variável } & \multicolumn{2}{|c|}{ Y1 } \\
\hline & $\begin{array}{l}\text { Coeficiente de } \\
\text { Correlação }\end{array}$ & $\begin{array}{c}\text { Sig. }(2 \\
\text { extremidades })\end{array}$ \\
\hline Y1 - Percepção de negócio (variável dependente) & 1 & \\
\hline AC1- Eu faço planejamentos técnicos para as safras para que a produção da lavoura melhore. & 0,183 & 0,17 \\
\hline AC2- Conheço as técnicas para melhorar os resultados da produção da minha lavoura. & 0,065 & 0,626 \\
\hline AC3- Pago cursos de aperfeiçoamentos para meus funcionários. &, $336^{*}$ & 0,01 \\
\hline AC4- Procuro orientação técnica dos órgãos que apoiam os produtores rurais. & 0,216 & 0,104 \\
\hline $\begin{array}{l}\text { AC5- Coloco em prática as mudanças técnicas que conheci através dos órgãos de apoio ao } \\
\text { agricultor. }\end{array}$ &, $442^{* *}$ & 0,001 \\
\hline Clientes1 - Conheço as preferências e gostos de meus clientes. & $-0,082$ & 0,539 \\
\hline $\begin{array}{l}\text { Clientes } 2 \text { - Modifico minha forma de conduzir o meu negócio como agricultor para } \\
\text { atender às solicitações dos meus clientes (corretor, cliente final, supermercados, cafeteiras, } \\
\text { distribuidores, exportação). }\end{array}$ & 0,09 & 0,502 \\
\hline Clientes3 - Tenho plano definido para enfrentar meus concorrentes. &, $519^{* *}$ & 0 \\
\hline Clientes4 - Considero que meu produto é diferenciado (melhor) que o de seu concorrente. &, $434^{* *}$ & 0,001 \\
\hline Interna1 - Faço planejamento interno para me preparar para as mudanças no mercado. &, $334^{*}$ & 0,011 \\
\hline Interna2 - Meu negócio tem Missão e objetivos definidos & 0,143 & 0,285 \\
\hline Interna3 -Os processos de produção da minha propriedade estão totalmente definidos. &, $349^{* *}$ & 0,007 \\
\hline $\begin{array}{l}\text { Interna4 - Separo as atividades da produção agrícola da minha propriedade das atividades } \\
\text { do dia-a-dia da minha família. }\end{array}$ & ,349** & 0,007 \\
\hline Interna5 - Minha propriedade tem divisões de tarefas definidas (por talhão, forma de produção). &, $327^{*}$ & 0,012 \\
\hline Interna6 - Minha propriedade cumpre as divisões de tarefas estabelecidas. & ,329* & 0,012 \\
\hline Fin1 - Conheço os custos fixos da minha propriedade agrícola. & 0,247 & 0,062 \\
\hline Fin2 - Conheço os custos variáveis da minha propriedade agrícola. &, $473^{* *}$ & 0 \\
\hline Fin3 - Conheço a receita que cada talhão dá. & 0,252 & 0,056 \\
\hline $\begin{array}{l}\text { Fin } 4 \text { - Planejo o atendimento das necessidades da minha propriedade conforme os } \\
\text { resultados financeiros da atividade agrícola da propriedade. }\end{array}$ &, $265^{*}$ & 0,044 \\
\hline $\begin{array}{l}\text { Fin } 5 \text { - Trato as necessidades financeiras da minha família separadamente das necessidades } \\
\text { financeiras da atividade agrícola da propriedade }\end{array}$ & 0,238 & 0,072 \\
\hline $\begin{array}{l}\text { Fin6- Tenho definido a forma para calcular o salário de cada membro da propriedade, } \\
\text { inclusive o meu, conforme a tarefa que desempenha na atividade agrícola da propriedade. }\end{array}$ &, $299^{*}$ & 0,022 \\
\hline $\begin{array}{l}\text { Fin7- Planejo mudanças nos processos de produção para que a minha produção tenha } \\
\text { menores custos. }\end{array}$ & 0,108 & 0,422 \\
\hline
\end{tabular}

Fonte: Dados da Pesquisa. Elaborado pelos autores

Nota:*. A correlação é significativa no nível 0,05 (2 extremidades);**. A correlação é significativa no nível 0,01 (2 extremidades)

Os resultados da Tabela 2 sugerem que há associação estatisticamente significante, ao nível de $5 \%$, entre a variável dependente Y1 e, AC3, Interna1, Interna5, Interna6, Fin4 e Fin6. E há associação, ao nível de 1\% de significância, entre a variável dependente Y1 e AC5, Clientes3, Clientes4, Interna3, Interna4 e Fin2.

Nesse sentido, pelo teste de Spearman, somente as variáveis AC3, AC5, Clientes3, Clientes4, Interna1,
Interna3, Interna4, Interna5, Interna6, Financ2, Financ4 e Financ6 possuem associação estatística significante com a variável dependente Y1. Ou seja, os cafeicultores familiares, somente associam como negócio: Pago cursos de aperfeiçoamentos para meus funcionários; Coloco em prática as mudanças técnicas que conheci através dos órgãos de apoio ao agricultor; Tenho plano definido para enfrentar meus concorrentes; Considero que meu 
produto é mais diferenciado (melhor) do que o de seu concorrente; Faço planejamento interno para me preparar para as mudanças no mercado; Os processos de produção da minha propriedade estão totalmente definidos; Separo as atividades da produção agrícola da minha propriedade das atividades do dia-a-dia da minha família; Minha propriedade tem divisões de tarefas definidas (por talhão, forma de produção); Minha propriedade cumpre as divisões de tarefas estabelecidas; Conheço os custos variáveis da minha propriedade agrícola; Planejo o atendimento das necessidades da minha propriedade conforme os resultados financeiros da atividade agrícola da propriedade; Tenho definido a forma para calcular o salário de cada membro da propriedade, inclusive o meu, conforme a tarefa que desempenha na atividade agrícola da propriedade.

\subsection{Modelo de Regressão Ordinal}

$\mathrm{Na}$ regressão ordinal, foram testadas as cinco funções Link, de maneira a obter um modelo parcimonioso, que seja válido, e com um número mínimo de variáveis independentes significativas (MARÔCO, 2014). Isso porque, conforme Tabela 3 a distribuição dos dados da variável dependente não obedeceu às recomendações de Marôco (2014).

Para identificar qual a melhor recomendação feita por Marôco (2014), utilizou-se a variável dependente Y1. As frequências das respostas se alternaram entre, discordo, não sei responder, concordo; gerando uma mediana 3 , para a resposta não concordo nem discordo - Tabela 3.

Cabe informar que a pergunta "Minha propriedade está preparada para enfrentar as mudanças do mercado, foi a nomenclatura da variável dependente deste artigo, Y1, denominada de "Percepção de Negócio".

Assim, testaram-se inicialmente, em relação à Y1, todas as 21 variáveis. Dessas verificações, não se extraiu um modelo adequado, dado que o Pseudo $\mathrm{R}^{2}$ foi da ordem $100 \%$ e não houve significância com as variáveis independentes.
Em seguida, foram realizados outros testes de regressão ordinal em relação à Y1: com cada uma das 21 variáveis, individualmente; e com os construtos agrupados por perspectivas. Nos testes de cada variável, por exemplo, com a função Link Logit, foram significativas a $5 \%$ e os modelos validados pelo teste de linhas paralelas para as seguintes variáveis: AC3, Clientes4, Interna1, Interna4, Interna5, Interna6, Fin2, Fin3, Fin4.

Na sequência, foi testada a regressão ordinal, para cada função Link, das variáveis que foram significativas simultaneamente na Correlação de Spearman e nas regressões ordinais individualizadas das variáveis. Foi indicado um modelo válido, obtido na "Regressão Comum". Por exemplo, as variáveis que foram comuns aos dois testes estatísticos, considerando para a regressão ordinal Logit, foram AC3, Clientes4, Interna1, Interna4, Interna5, Interna6, Financ2 e Financ4. Nesse caso, algumas variáveis não foram significativas, dado que pode haver interação entre as variáveis independentes.

Em seguida, foram realizados outros testes, sempre considerando e utilizando as cinco funções Link, com as variáveis que se mostraram significativas na "Regressão Comum". Reaplicou-se então o modelo de regressão, e obteve-se um modelo ajustado e validado em relação à variável dependente, denominado "Regressão Final", cujas variáveis estatisticamente significantes foram: Interna4 e Fin4.

Os resultados com as cinco funções Link do software foram, de maneira geral, similares ou próximos, para os modelos com as funções Link LogLog complementar e Logit. Ao se tentar estabelecer um modelo com as duas variáveis Interna4 e Fin4, nessa ordem, foram obtidos ajustes melhores, conforme resultado da verossimilhança no teste de linhas paralelas. Destaca-se que os modelos com as funções Cauchit, Probit e Log-Log negativo, mostraram-se impróprios para análise estatística - Tabelas 4 e 5.

TABELA 3 - Variável dependente - Y1

\begin{tabular}{|c|c|c|c|c|c|c|}
\hline Classe & Frequência & Porcentagem (\%) & Moda & Mediana & Média & Desvio-Padrão \\
\hline 1 & 4 & 6,9 & & & & \\
\hline 2 & 15 & 25,9 & & & & \\
\hline 3 & 16 & 27,6 & 4 & 3 & 3,03 & $-1,02$ \\
\hline 4 & 21 & 36,2 & & & & \\
\hline 5 & 2 & 3,4 & & & & \\
\hline
\end{tabular}

Fonte: Dados da Pesquisa

Nota: Y1 - Percepção de negócio

Organizações Rurais \& Agroindustriais, Lavras, v. 21, n.1-3, p. 173-185, 2019 
TABELA 4 - Regressão final

\begin{tabular}{|c|c|c|c|c|}
\hline Modelo & Verossimilhança de $\log -2$ & Qui-quadrado & df & Sig. \\
\hline Somente interceptação & 97,128 & & & \\
\hline Final & 48,885 & 48,243 & 8 &, 000 \\
\hline \multicolumn{5}{|l|}{ Adequação do ajuste } \\
\hline Pearson & 36,523 & - & 52 & 949 \\
\hline Desviância & 39,428 & - & 52 & ,900 \\
\hline \multicolumn{5}{|l|}{ Pseudo R quadrado } \\
\hline Cox e Snell &, 565 & & & \\
\hline Nagelkerke & ,603 & - & - & \\
\hline McFadden & ,303 & & & \\
\hline \multicolumn{5}{|c|}{ Teste de linhas paralelas ${ }^{a}$} \\
\hline Modelo & Verossimilhança de $\log -2$ & Qui-quadrado & df & Sig. \\
\hline Hipótese nula & 48,885 & & & \\
\hline Geral & 47,855 & 1,030 & 24 & 1,000 \\
\hline
\end{tabular}

Fonte: Dados da Pesquisa

Nota: a 47 (58,8\%) células (ou seja, os níveis da variável dependente por combinações observadas de valores da variável de predictor) com zero frequências.

TABELA 5 - Estimativas e significância do modelo de regressão final

\begin{tabular}{|c|c|c|c|}
\hline CONSTRUTO & ESTIMATIVA & ERRO PADRÃO & SIG. \\
\hline$[\mathrm{Y} 1=1]$ & $-20,863$ &, 827 &, 000 \\
\hline$[\mathrm{Y} 1=2]$ & $-18,989$ & ,671 &, 000 \\
\hline$[\mathrm{Y} 1=3]$ & $-17,909$ & ,621 &, 000 \\
\hline$[\mathrm{Y} 1=4]$ & $-15,932$ & ,611 &, 000 \\
\hline$[$ Interna4=1] & $-18,092$ &, 520 &, 000 \\
\hline$[$ Interna4=2] & $-17,984$ & ,446 & 0,000 \\
\hline$[$ Interna4=3] & $-17,249$ & ,486 &, 000 \\
\hline$[$ Interna4=4] & $-16,825$ & 0,000 & \\
\hline$[$ Interna4=5] & $0^{\mathrm{a}}$ & & \\
\hline$[$ Financ4=1] & 1,330 & 1,056 & ,208 \\
\hline [Financ4=2] & $-1,478$ & ,660 &, 025 \\
\hline [Financ4=3] &,- 713 & ,766 & ,352 \\
\hline [Financ4=4] &,- 342 &, 592 &, 564 \\
\hline$[$ Financ4=5] & $0^{\mathrm{a}}$ & & \\
\hline
\end{tabular}

Fonte: Dados da Pesquisa. Elaborado pelos autores

Nota: Y1 - Percepção de negócio

Interna4 - Separo as atividades da produção agrícola da minha propriedade das atividades do dia-a-dia da minha família.

Financ4- Planejo o atendimento das necessidades da minha propriedade conforme os resultados financeiros da atividade agrícola da propriedade

No modelo de "Regressão Final", observa-se que o padrão ajustado proporcionou uma significância a $1 \%$, sendo melhor do que o modelo nulo; pois ao menos uma variável independente afeta de maneira significativa a probabilidade de ocorrência na variável Y1. $\mathrm{O}$ resultado do pseudo $\mathrm{R}^{2} \mathrm{McF}$ adden indica que as variáveis 
independentes explicam 30\% da percepção de negócios (Y1) dos respondentes (cafeicultores). Quanto ao pressuposto da homogeneidade dos declives, os resultados indicam que o modelo atende a $100 \%$ de confiança - Tabela 4 .

Os resultados da Tabela 5 indicam que apenas as variáveis Interna4 e Fin4 possuem relação com Y1, sugerindo que, os respondentes têm uma percepção de negócio muito limitada. Está restrita a saber separar as atividades da produção agrícola da propriedade das atividades diárias da família; e planejar as necessidades da propriedade. As demais dimensões do BSC parecem serem desconhecidas pelos cafeicultores.

\subsection{Interpretação dos Resultados}

Os parâmetros do BSC que nortearam esta pesquisa sustentam que a lucratividade de um negócio depende da capacidade do gestor de dominar os fundamentos da gestão, ou seja, depende da maturidade da gestão. É isso que definirá uma gestão bem-sucedida (EYERKAUFER; OLINQUEVITCH, 2007; SOTHE; DRESEL; DILL, 2014). Quando alguns desses parâmetros são desconsiderados, a capacidade de percepção de negócio é negativamente afetada; comprometendo o alcance da maturidade da gestão empresarial (PACHECO; GOMES, 2016; SOTHE; DRESEL; DILL, 2014; TEIXEIRA; PEREIRA, 2014; FREZATTI et al., 2014; COE; LETZA, 2014; QUEIROZ, 2013; SILVA; DACORSO, 2013; MAFUD, CASTRO; NEVES, 2009; PETRY; NASCIMENTO, 2009; EYERKAUFER; OLINQUEVITCH, 2007; GUILHOTO, 2007; WANDERLEY, 2006; SHADBOLT; RAWLINGS, 2000).

Esta pesquisa relacionou Perspectiva de Negócio (Y1) dos cafeicultores familiares do Caparaó aos parâmetros de desempenho do BSC, e identificou que, a amostra em questão, tem conhecimentos muito limitados sobre os indicadores de desempenho. Os resultados sugeriram que não existe a maturidade da gestão empresarial. Ou seja, a capacidade de gerenciamento dos cafeicultores feriu os princípios do modelo de gestão de desempenho BSC. Os resultados sugerem que os cafeicultores familiares não utilizam os parâmetros do BSC para a busca da maturidade gerencial da empresa. Com isso, não estabelecem estratégias, nem mensuram seus desempenhos. Consequentemente, não há alteração em seu desempenho empresarial.

Diante das perspectivas que os resultados apontaram para esta amostra, cabe ressaltar a importância em profissionalizar os cafeicultores familiares; incentivá-los a buscar capacitação para gerenciamento de negócio rural. Isso ampliaria sua capacidade de otimizar a utilização de recursos e alcançar melhor desempenho empresarial.

Os resultados encontrados corroboram com os estudos de Lourenzani (2006) Queiroz (2004) e Roder e Silva (2013) quando se aborda que o momento da agricultura é de ampliar o conhecimento para o mercado vasto de tecnologia e gerenciamento rural.

Também reforçam os princípios da teoria do BSC neste estudo, quando indicou a falta de percepção de negócio ou falta de conhecimento dos parâmetros gerenciais dos cafeicultores familiares (FREZATTI et al., 2014; COE; LETZA, 2014; SOTHE; DRESEL; DILL, 2014; TEIXEIRA; PEREIRA, 2014; QUEIROZ, 2013; MAFUD; CASTRO; NEVES, 2009; PETRY; NASCIMENTO, 2009; EYERKAUFER; OLINQUEVITCH, 2007; GUILHOTO, 2007; WANDERLELY, 2006; SHADBOLT; RAWLINGS, 2000; PACHECO; GOMES, 2016; SILVA; DACORSO, 2013).

Reitera os argumentos de Sothe, Dresel e Dill, 2014; Teixeira e Pereira, 2014, Eyerkaufer e Olinquevitch, 2007; Guilhoto, 2007; Lourenzani, 2005; Queiroz (2004) quanto à falta de conhecimento gerencial, e da necessidade de superar a deficiência da gestão empresarial na agricultura familiar.

Como destaque importante, observou-se que os estudos de Queiroz (2004) e Lourenzani (2005), buscam integralizar um sistema de gerenciamento para os agricultores familiares. Contudo, para a amostra desta pesquisa, os dados sugerem que não se recomenda implantar ou desenvolver um modelo de gerenciamento baseado nas perspectivas do BSC, pois a percepção de negócio dos cafeicultores é insuficiente para compreender, implantar e continuar um processo de planejamento estratégico.

Sabendo-se que maturidade empresarial está diretamente ligada ao conhecimento interno ao longo da vida organizacional, e à capacidade de transformar conhecimento em resultados, se não existe conhecimento não há a possibilidade de resultados dentro da perspectiva do BSC haja vista que eles são efeitos da maturidade empresarial.

\section{CONCLUSÃO}

O objetivo deste estudo foi identificar a maturidade da gestão de pequenas unidades agricultoras, utilizando a metodologia do BSC. Os resultados sugerem que, para esse grupo amostral, não há uma percepção de negócio dentro dos parâmetros do BSC. Eles não possuem conhecimento informacional suficientes para minimizar o risco nas 
tomadas de decisão, nem maturidade gerencial. As respostas ao problema de pesquisa proposto - Os agricultores cafeeiros familiares da amostra deste estudo utilizam os parâmetros do BSC para conduzir seus negócios? - foram negativas.

Por isso entendeu-se que esse grupo amostral necessita de mais acesso à informação ou formação em gerenciamento de negócio. Isso poderia ser iniciado com aprendizado sobre funcionamento de um mercado e o comportamento do produtor e do consumidor, dentro dele. Além de desenvolver o conhecimento gerencial o agricultor poderá ampliar a capacidade de desenvolvimento econômico da propriedade.

A despeito dos resultados encontrados, este estudo também tem limitações. A começar com o tamanho da amostra, e por ser não probabilística; ter utilizado um único modelo de gestão como parâmetro de identificação de percepção de negócio dos respondentes; não considerar a aplicação plena do BSC, somente suas perspectivas para avaliação da maturidade de gestão. Contudo, para o pequeno agricultor familiar cafeeiro, perceber a maturidade da gestão corresponde a dar um passo em direção a uma gestão baseada em parâmetros técnicos. Nesse sentido, os parâmetros do BSC são muito úteis para delimitar um comportamento gerencial mais eficiente por parte dos pequenos agricultores cafeeiros.

Diante disso, sugere-se a realização de pesquisas futuras com amostra maior, de outras regiões; outros setores da agricultura familiar; com amostra probabilística; utilizar outras ferramentas de medida de desempenho para analisar a percepção do agricultor.

Além de desenvolver o conhecimento gerencial o agricultor poderá ampliar a capacidade de desenvolvimento econômico da propriedade após possuir conhecimento suficiente para implantar um modelo de gestão baseado na metodologia de desempenho do BSC.

\section{REFERÊNCIAS}

ABRAMOVAY, R.; VEIGA, J. E. Novas Instituições para o Desenvolvimento Rural: o Caso do Programa Nacional de Fortalecimento da Agricultura Familiar (PRONAF), IPEA, Texto para Discussão ${ }^{\circ}$ 641, e-ISSN 1415-4765, 1999.

ACS, Zoltan J.; KALLAS, Kadri. State of literature on small-to medium-sized enterprises and entrepreneurship in low-income communities. In: Entrepreneurship in emerging domestic markets. Springer, Boston, MA, 2008. p. 21-45.
COE, Nicholas; LETZA, Steve. Two decades of the balanced scorecard: A review of developments. The Poznan University of Economics Review, v. 14, n. 1, p. 63, 2014.

CROZATTI, Jaime. Modelo de gestão e cultura organizacional: conceitos e interações. Caderno de estudos, n. 18, p. 01-20, 1998.

EMPRESA DE ASSISTÊNCIA TÉCNICA E EXTENSÃO RURAL DE MINAS GERAIS. Assistência Técnica e Extensão Rural de qualidade para todos - Presidente da Emater-MG fala sobre desafios e propostas para a extensão rural e agricultura familiar. Belo Horizonte, 2016. Disponível em: http://www.emater.mg.gov.br/portal. cgi?flagweb=site_tpl_paginas_internas\&id=18354\#. WiSaU9KnFdg. Acesso em: 03 dez. 2017.

EYERKAUFER, M. L. Contabilidade Gerencial na Gestão de Propriedades Rurais: Um estudo das Propriedades Leiteiras no Extremo Oeste do Estado de Santa Catarina. 2007. 139 f. 2007 . Tese de Doutorado. Dissertação (Mestrado em Contabilidade) - Programa de Pós-Graduação de Ciências Contábeis do Centro de Ciências Sociais e Aplicadas da Universidade Regional de Blumenau-FURB.

FAUTH, E. M. Agricultura familiar: força revigorada. Indicadores Econômicos FEE, v. 34, n. 3, p. 25-34, 2006.

FINATTO, R. A.; SALAMONI, G. Agricultura familiar e agroecologia: perfil da produção de base agroecológica do município de Pelotas/RS. Sociedade \& Natureza, v. 20, n. 2, p. 199-217, 2008.

FREZATTI, F.; BIDO, D. S.; CRUZ, A. P. C.; MACHADO, M. J. C. O papel do Balanced Scorecard na Gestão da Inovação. RAE-Revista de Administração de Empresas, v. 54, n. 4, p. 381-392, 2014.

GAITÁN-CREMASCHI, D. et al. Assessing the sustainability performance of coffee farms in Vietnam: a social profit inefficiency approach. Sustainability, v. 10, n. 11 , p. 4227,2018 ..

GUILHOTO, Joaquim et al. A Importância Da Agricultura Familiar No Brasil E EM Seus Estados (Family Agriculture's GDP in Brazil and in It's States). V Encontro Nacional da Associação Brasileira de Estudos Regionais e Urbanos, 2007. Disponível em: https://ssrn.com/abstract=2408072. 
HO, T. Q. et al. Which farming systems are efficient for Vietnamese coffee farmers?. Economic Analysis and Policy, v. 56, p. 114-125, 2017.

INSTITUTO CAPIXABADE PESQUISA, ASSISTÊNCIA TÉCNICA E EXTENSÃO RURAL. Disponível em: https://incaper.es.gov.br/. Acesso em 05 mai. de 2017.

KAGEYAMA, A. A. Desenvolvimento rural: conceitos e aplicação ao caso brasileiro. Porto Alegre, 2008.

KAPLAN, R. S.; NORTON, D. P. Having trouble with your strategy? Then map it. Harvard Business Review, v. 78, n. 5, p. 167-176, 2000.

KULAWCZUK, P. The development of entrepreneurship in rural areas. In: Kimball, J. D. (Eds.). The Transfer of Power: Decentralization in Central and Eastern Europe. Budapest, Hungary: The Local Government and Service Form Initiative, p. 97-109, 1998.

LINH, V. H. Efficiency of rice farming households in Vietnan. International Journal of Development Issues, v. 11, n. 1, p. $60-73,2012$.

LOURENZANI, L. W.; PINTO, B. L. Proposta metodológica para a capacitação gerencial de agricultores familiares. In: CONGRESSO DA SOCIEDADE BRASILEIRA DE ECONOMIA, ADMINISTRAÇÃO E SOCIOLOGIA RURAL (SOBER), 44., 2006, Tupã. Anais... Tupã: Sociedade Brasileira de Economia, Administração e Sociologia Rural (SOBER), 2006.

LOURENZANI, W. L. Modelo dinâmico para a gestão integrada da agricultura familiar. 2005. $210 \mathrm{f}$. Teste (Doutorado em Engenharia de Produção) - Programa de Pós-Graduação em Engenharia de Produção da Universidade Federal de São Carlos, São Carlos. 2005.

LOURENZANI, W. L.; QUEIROZ, T. R.; SOUZA FILHO, H. M. Strategic Mapping of the Rural Firm: A Balanced Scorecard Approach. In: CONGRESS DEVELOPING ENTREPRENEURSHIP ABILITIES TO FEED THE WORLD IN A SUSTAINABLE WAY, 15., 2005, Campinas. Anais... Campinas: International Farm Management Association, 2005.

LOURENZANI, W. L. Modelo Dinâmico para a gestão integrada de Empreendimentos Rurais. In: CONGRESSO INTERNACIONAL DE DINÂMICA DE NEGÓCIOS, 1 ., 2006, Brasília. Anais... Brasília: SBDS, 2006.
MAFUD, M. D.; CASTRO, L. T.; NEVES, M. F. (2009). Desafios da Pequena Propriedade. Brasília, DF - Brasil. Signatura: BR0902656. 2009

MARÔCO, J. Regressão ordinal. Análise estatística: com utilização do SPSS. 3. ed. Portugal: Edições Sílabo, 2014.

MATADE MINAS. Dados da Região. Disponível em: http:// www.matasdeminas.org.br. Acesso em 05 de maio 2017.

MURDOCH, J. Networks - a new paradigma of rural development? Journal of Rural Studies, v. 16, n. 4, p. 407-419, 2000.

NIVEN, P. R. Balanced Scorecard: Step-by-step for government and nonprofit agencies. John Wiley \& Sons, 2011.

OZGEN, E.; MINSKY, B. D. Opportunity recognition in rural entrepreneurship in developing countries. International Journal of Entrepreneurship, v. 11, p. 49, 2007.

PACHECO, L. M.; GOMES, E. J. Modelos de gestão da inovação em uma perspectiva comparada: contribuição para aplicação em pequenas e médias empresas. Revista da Micro e Pequena Empresa, v. 10, n. 1, p. 63-79, 2016.

PETRIN, T.; GANNON, A. Rural development through entrepreneurship. FAO, Rome (Italy). Regional Office for Europe, 1997. Disponível em: http://agris.fao.org/ agrissearch/search/display.do?f=1998/XF/XF98005.xml; F1998077983. Acesso em: 05 mai. 2017.

PETRY, L. I.; NASCIMENTO, A. M. et. al. Um estudo sobre o modelo de gestão e o processo sucessório em empresas familiares. Revista de Contabilidade \& Finanças, v. 20, p. 109-125, 2009.

QUEIROZ, J. B. P. de. A educação do campo no Brasil e a construção das escolas do campo. Revista NERA, Presidente Prudente, v. 14, n. 18, p. 37-46, 2011. Disponível em: http://revista.fct.unesp.br/index.php/nera/ article/view/1347. Acesso em: 05 mai. 2017.

QUEIROZ, T. R. Sistema de custeio e indicadores de desempenho para a agricultura familiar. 2004. 140p. Dissertação (Mestrado em Engenharia de Produção) Departamento de Engenharia de Produção, Universidade Federal de São Carlos, São Carlos, 2004.

Organizações Rurais \& Agroindustriais, Lavras, v. 21, n.1-3, p. 173-185, 2019 
RODER, E. S. F.; SILVA, E. L. Agricultura familiar e as teses de doutorado no Brasil. TransInformação, Campinas, v. 25, n. 2, p. 111-126, 2013.

ROHM, H.; HALBACH, L. Developing and using Balanced Scorecard performance systems. The Balanced Scorecard Institute, 2005.

ROMEIRO, V. M. B. Gestão da pequena unidade de produção de citros: uma análise dos fatores influentes no sucesso do empreendimento do ponto de vista do produtor de Bebedouro (SP). 2002. 242 p. Dissertação (Mestrado em Engenharia de Produção). Escola de Engenharia de São Carlos, Universidade de São Paulo, São Carlos, 2002.

ROSA, B.T., et al.,(2017). Good Agricultural Practices in na Association of Familiar Coffee Prducers by Means of Clusters Analysis. Coffee Science, v. 12, n. 1, p. 49-59.

SANTOS, M.; SILVEIRA, M. L. O Brasil: território e sociedade no início do século XXI. Rio de Janeiro: Record, 2008.

SENAR. Serviço Nacional de Aprendizagem Rural, 2015. Disponível em: http://www.senar.org.br. Acesso em 05 mai. de 2017.

SHADBOLT, N. M.; RAWLINGS, K. M. An exploration of the use of the balanced scorecard approach to achieve better farm business planning and control. Agrobusiness Perspectives, v. 20, n. 32, 2000

SILVA, G.; DACORSO, A. L. R. Inovação aberta como uma vantagem competitiva para a micro e pequena empresa. Revista de Administração e Inovação, v. 10, n. 3, pp. 251-268, 2013.
SOTHE, A.; DRESEL, M.; DILL, R.P. Diagnóstico da Agricultura Familiar: Identificação das Ferramentas e Informações Gerenciais nas Propriedades dos Municípios De Salvador Das Missões-RS e Tunápolis-SC. XVII SemeAd, Seminário de Administração. Anais... SemeAd, 2014.

SPROESSER, R. L. et al. Modelo de Planejamento Estratégico Para Agricultura Familiar Coletiva. In: IV simpósio sobre recursos naturais e socioeconômicos do Pantanal. Corumbá, MS. Anais... Corumbá, MS. Simpan, 2004.

TEIXEIRA, S. A.; PEREIRA, A. C. Planejamento Financeiro de Curto Prazo Como Ferramenta de Gestão na PME. UNOPAR Científica Ciências Jurídicas e Empresariais, v. 2, n. 2, 2014.

TOMEI, P. A.; LIMA, D. A. A. Análise das barreiras que dificultam a transformação do agricultor familiar em empreendedor rural no contexto brasileiro. Revista Ibero-Americana de Estratégia, v. 13, n. 3, p. 107, 2014.

WANDERLEY, M. N. B. Juventude rural: vida no campo e projetos para o futuro. Relatório de pesquisa, 2006.

. O mundo rural como um espaço de vida: reflexões sobre a propriedade da terra, agricultura familiar e ruralidade. Porto Alegre: Editora da UFRGS, 2009.

- Agricultura familiar e campesinato: rupturas e continuidade. Estudos Sociedade e Sgricultura, v. $1,2013$.

ZHANG, Y.; CHEN, Y. Applying BSC-Based Resource Allocation Strategy to IDSS Intelligent Prediction. Journal of Software, v. 11, n. 6, p. 569-576, 2016. 